MEDICAL ETHICS

\title{
Rural and non-rural differences in membership of the American Society of Bioethics and Humanities
}

\author{
William Nelson, William B Weeks
}

J Med Ethics 2006;32:41 1-413. doi: 10.1136/jme.2005.014183

See end of article for authors' affiliations

a.....................

Correspondence to: Dr William Nelson, Department of Community and Family Medicine,

Dartmouth Medical

School, 7251

Strasenburgh Hall

Hanover, NH 03755 USA;

william.a.nelson@

dartmouth.edu

Received 29 August 2005

Accepted for publication

7 September 2005

\begin{abstract}
Objective: To determine whether bioethicists are distributed along a rural-to-urban continuum in a way that reflects potential need of those resources as determined by the general population, hospital facilities and hospital beds.

Methods: US members of a large, multidisciplinary professional society, the American Society of Bioethics and Humanities (ASBH), the US population, hospital facilities and hospital beds were classified across a four-tier rural-to-urban continuum. The proportion of each group in rural settings was compared with that in urban settings, and odds ratios were calculated with $95 \%$ confidence intervals.

Results: Although $91 \%$ of ASBH members live or work in urban settings, only $66 \%$ of the US population did so. In contrast, $2 \%$ of ASBH members live or work in rural settings compared with $13 \%$ of the population. ASBH members were 10.7 times $(95 \% \mathrm{Cl} 6.6$ to 17.3$)$ as likely to be represented in urban than in rural settings when compared with the general population, 25.6 times $(95 \% \mathrm{Cl} 15.8$ to 41.5$)$ and 6.9 times (95\% Cl 4.3 to 11.1 ) as likely with regard to hospital facilities and hospital beds, respectively.

Conclusions: Using various comparisons it was found that ASBH members are under-represented in rural as compared with urban settings. Although not all bioethicists are ASBH members, these findings suggest that the availability of professional bioethical resources may be inadequate in rural America. The disparities that were found may have considerable effect on ethics scholarship, research, ethical committees and education, and adds to the argument that rural American communities are under-served.
\end{abstract}

$\mathrm{R}$ ural healthcare professionals, similar to their non-rural counterparts, must deal with ethical conflicts that may pose barriers to good quality patient care. The 2000 US census indicates that more than 39 million people or 14\% of the overall US population live in rural communities, ${ }^{1}$ those that have less than 2500 people per town boundary. ${ }^{2}$

Several authors have suggested that heathcare ethics issues in rural settings are considerably influenced by the unique rural context. ${ }^{2-10}$ The rural community is not identified only by its small population density and distance to an urban setting but also by a combination of social, religious, geographical, cultural, economic and health-related factors. For example, rural areas in the US have a greater overall ageadjusted mortality, a higher proportion of chronic illness and life-threatening conditions, a higher proportion of children and the elderly, and a greater prevalence of environmental hazards than in metropolitan communities. ${ }^{2-11}$ These characteristics, coupled with disparities in access to quality healthcare services, such as expensive medical technologies and specialty care, influence rural healthcare ethical conflicts. ${ }^{12412}$ Just as the urban setting influences ethical conflicts, ${ }^{13}$ the rural context is interwoven into the fabric of ethical issues and the response to those issues in rural America.

When healthcare professionals, regardless of their setting, encounter ethical conflicts, they generally respond to the conflict based on their personal values and experiences, ethics training, professional guidelines and codes and organisational policies. In addition, healthcare professionals may seek the advice of an ethics committee or the literature on ethics. It has, however, been noted that unlike their urban counterparts, many US rural healthcare professionals and facilities do not have ethics committees available to help them deal with the ethical conflicts. ${ }^{4-6}{ }^{14}$ Publications on ethics focusing specifically and substantively on rural healthcare conflicts seem to be limited..$^{4615}$ As a result of resource limitations in ethics dealing with challenges unique to the rural environment, we wanted to systematically determine whether the limitation of resources also includes the availability of professionals engaged in bioethics activities.

The American Society of Bioethics and Humanities (ASBH) is a large multidisciplinary professional society with the stated purpose "to promote the exchange of ideas and foster multidisciplinary, interdisciplinary, and interprofessional scholarship, research, teaching, policy development, professional development, and collegiality among people engaged in all of the endeavors related to clinical and academic bioethics and the health-related humanities."16 Assuming that ASBH membership represents a useful cross-section of professional resources for healthcare ethics, we used the ASBH membership list to determine whether members were distributed along the rural-urban continuum in a way that reflected potential need of those resources.

\section{METHODS}

To determine the availability of professional resources for healthcare ethics, we used the 2004 registry of ASBH members. This registry contains individual-level data on the ASBH members including their preferred mailing address and zipcode. We used two methods to determine the potential need for those professional bioethics resources. Firstly, from the 2000 US census data, we obtained information on the distribution of the general population. Secondly, we used the registry of the American Hospital Association to obtain the number of general medical and surgical facilities and number of beds for the year 2003.

To determine the distribution of professional resources and potential need across the rural-urban continuum, we used Rural-Urban Commuting Area codes developed by the Health

Abbreviation: ASBH, American Society of Bioethics and Humanities 
Resources and Service Administration's Federal Office of Rural Health Policy the Department of Agriculture's Economic Research Service, and the WWAMI Rural Health Research Center at the University of Washington School Of Medicine. We used the Washington State Department of Health's four-tiered Rural-Urban Commuting Area consolidation system to classify and compare urban core areas, suburban areas, large town areas and small town and isolated rural areas. ${ }^{17}$ In this study, we refer to small town and isolated rural area as rural areas. We matched zipcodes from all registries (ASBH, American Hospital Association and 2000 US census) to rural-urban commuting area codes, and aggregated according to the four-tier codes (table 1).

We calculated odds ratios (ORs) and $95 \%$ confidence intervals (CI) for ASBH members residing or working in rural and urban (urban core areas) settings and compared three different measures of potential engagement with ASBH members: the general population, hospital facilities and hospital beds.

\section{RESULTS}

The 2004 ASBH membership dataset included 1009 members. Ninety one per cent of the members were found to live or work in urban areas, $4 \%$ in suburban areas, $3 \%$ in large town areas and only $2 \%$ in rural areas. In contrast, $13 \%$ of the total US population was found to live in rural areas and $66 \%$ in urban settings (table 1).

Fifty four per cent of general medical and surgical hospitals were located in urban settings and $26 \%$ in rural areas (table 1). Those urban facilities, however, accounted for $76 \%$ of the beds compared with only $10 \%$ in rural areas (table 1 ). We found that the disparities in the distribution of ASBH members were more dramatic when examining the allocation of ASBH members to hospitals and hospital beds. In urban locations, there is about one ASBH member for every three hospitals, whereas in rural settings, about one ASBH member for every 100 hospitals. When hospital beds are taken as the denominator, there is one ASBH member for every 780 urban hospital beds, but only one for every 5360 rural hospital beds (table 1).

ASBH members were 10.7 times (95\% CI 6.6 to 17.3 ) more likely to be represented in urban than in rural settings when compared with the general population, 25.6 times (95\% CI 15.8 to 41.5 ) and 6.9 times (95\% CI 4.3 to 11.1 ) as likely with regard to hospital facilities and hospital beds, respectively.

\section{DISCUSSION}

Using several methods of comparison, we consistently found that ASBH members are under-represented in rural than in urban settings. Although not all bioethicists are ASBH members, these findings suggest that the availability of bioethics resources in rural settings may be inadequate. The disparities that we found may affect ethics scholarship, research, ethics committees, publications and education.

The literature on rural health emphasises unique characteristics that are reflective of rural settings compared with American non-rural settings. The rural characteristics considerably influence the nature of ethical conflicts in rural healthcare, ${ }^{211} 18-20$ including overlapping or dual providerpatient relationships, limited healthcare services and specialists, caregiver stress and a population that has a lower per capita income and poorer health status. ${ }^{12491121}$ The small number of rural ASBH members may hinder a robust dialogue of the relationship and influence of the rural context on the analysis of ethical issues or conflicts. This may explain the limited publications specially focusing on rural healthcare ethics issues. ${ }^{15}$

Additionally, if bioethics conferences or meetings are dominated by bioethicists from non-rural settings, as this study indicates, probably conference planners would focus on topics of interest to most attendees from urban settings. The rural bioethicists could arguably feel out of place because attending the conference is of minimum relevance to the challenges they experience. This may add credence to the perspective that much of ethics training is less relevant for those practising in rural setting. ${ }^{356}$

The study has several important limitations. Firstly, although ASBH is a leading professional organisation for bioethicists, membership is voluntary, so not all professionals engaged in various bioethics activities are members. Also, despite ASBH's stated mission to promote professionals engaged in "clinical and academic bioethics and the healthrelated humanities"16 we can not assume that all the members are bioethicists and work in healthcare facilities. All data on ASBH membership used for analysis was selfreported information, based on the member's preferred mailing address. It is possible that the preferred address may not match that of their actual work site. For example, a preferred address could be a home address in a metropolitan community and they commute to a rural site to work, or vice versa. At the time we analysed the 2004 ASBH data, data from the American Hospital Association for 2004 were not available yet, and therefore we used the 2003 dataset. For the general population, we used the 2000 US census data, which are the latest census population data available.

Despite these limitations, our findings suggest that the litany of limited rural healthcare ethics resources should also include bioethicists. Professional healthcare organisations and ethics educators should be aware of this potential problem and seek avenues to increase their focus and

Table 1 Summary statistics across rural-urban continuum

\begin{tabular}{|c|c|c|c|c|c|c|}
\hline RUCA* & ASBH members, $\mathbf{n}(\%)$ & $\begin{array}{l}\text { General US } \\
\text { population (\%) }\end{array}$ & Hospital facilities, $\mathbf{n}(\%)$ & $\begin{array}{l}\text { Ratio of } \\
\text { members to } \\
\text { hospital } \\
\text { facilities }\end{array}$ & Hospital beds, n (\%) & $\begin{array}{l}\text { Ratio of } \\
\text { member to } \\
\text { hospital } \\
\text { beds }\end{array}$ \\
\hline $\begin{array}{l}\text { Urban core } \\
\text { areas }\end{array}$ & $919(91)$ & 66.1 & $3221(54)$ & 0.29 & $717151(76)$ & $1: 780$ \\
\hline $\begin{array}{l}\text { Suburban } \\
\text { areas }\end{array}$ & $40(4) 4$ & 11.3 & $334(6)$ & 0.12 & 33287 (4) & $1: 832$ \\
\hline $\begin{array}{l}\text { Large town } \\
\text { areas }\end{array}$ & $33(3) 3$ & 9.5 & $835(14)$ & 0.04 & 106637 (11) & $1: 3231$ \\
\hline $\begin{array}{l}\text { Small town } \\
\text { and isolated } \\
\text { rural areas }\end{array}$ & $17(2)$ & 13.1 & $1525(26)$ & 0.01 & $91120(10)$ & $1: 5360$ \\
\hline Total & $1009(100)$ & 100 & $5915(100)$ & & $948195(100) \dagger$ & \\
\hline
\end{tabular}

ASBH, American Society of Bioethics and Humanity; RUCA, Rural-Urban Community Area.

*RUCA codes are defined according to Washington's State Department of Health's four-tiered RUCA consolidation system. ${ }^{17}$ tDoes not add up to exactly $100 \%$ because of approximation. 
availability regarding ethical issues that uniquely affect a large segment of the US population and healthcare professionals working in rural America. Strategies should be implemented that meet the needs of rural professionals.

How the rural characteristics affect both ethical conflicts and the responses to those conflicts have to be clearly understood. Research is needed to quantify ethical issues to a rural and non-rural stratification. Once such research has been carried out, ethics resources can be developed that are both culturally attuned and evidence based.

\section{ACKNOWLEDGEMENTS}

This work was supported by the Veterans' Rural Health Initiative, White River Junction, Vermont, USA. WBW was supported in part by VA Health Services Research and Development Grant REA 03-098. The views expressed in this article do not necessarily represent the views of the Department of Veterans Affairs or of the US government.

\section{Authors' affiliations}

W Nelson, Rural Ethics Initiatives, Department of Psychiatry, Dartmouth Medical School, Hanover, New Hampshire, USA

W B Weeks, Veterens' Rural Health Initiatives, Veterans Affairs Medical Center, White River Junction, Vermont, USA

\section{REFERENCES}

1 Weeks WB, Kazis LE, Shen Y, et al. Differences in health-related quality of life in rural and urban veterans. Am J Public Health 2004:94:1762-7.

2 Roberts LW, Battaglia J, Smithpeter M et al. An office on main street: health care dilemmas in small communities. Hastings Cent Rep 1999;29:28-37.

3 Nelson WA. Addressing rural ethics issues. Healthcare Exec 2004; 19:36-7.

4 Cook AF, Hoas $\mathrm{H}$. Voices from the margins: a context for developing bioethics-related resources in rural areas. Am J Bioethics 2001;1:W12.
5 Cook $\mathrm{AF}$, Hoas $\mathrm{H}$. Where the rubber hits the road: implications for organizational and clinical ethics in rural healthcare settings. HEC Forum 2000;12:331-40

6 Cook AF, Hoas H, Guttmannova K. Bioethics activities in rural hospitals. Camb Q Healthcare Ethics 2000;9:230-8.

7 Bushy A. When your client lives in a rural area. Part I: rural health care delivery issues. Issues Ment Health Nurs 1994;15:253-66.

8 Kelly SE. Bioethics and rural health: theorizing place, space, and subjects. Soc Sci Med 2003:56:2277-88.

9 Gamm LD, Hutchison LL, Dabney BJ, et al. Rural healthy people 2010: a companion document to Healthy People 2010, Vol 1. College Station, Texas: The Texas A\&M University System Health Science Center, School of Rural Public Health, Southwest Rural Health Research Center, 2003.

10 Ricketts TC. The changing nature of rural health care. Annu Rev Public Health 2000;21:639-57.

11 Roberts LW, Battaglia J, Epstein RS. Frontier ethics: mental health care needs and ethical dilemmas in rural communities. Psychiatr Serv 1999;50:497-503.

12 Weeks WB, Yano EM, Rubenstein LV. Primary care practice management in rural and urban veterans health administration settings. J Rural Health 2002; 18:298-303.

13 Blustein J. Setting the agenda for urban bioethics. J Urban Health 2001;78:7-20.

14 Moss AH. The application of the task force report in rural and frontier settings. J Clin Ethics 1999; 10:42-8.

15 Nelson WA, Lushkov G, Pomerantz A, et al. Rural health care ethics: is there a literature? Am J Bioethics 2006;6:44-50.

16 American Society for Bioethics and Humanities. Purpose of the ASBH. http:// www.asbh.org/about/purpose/htm. (accessed 26 Aug 2005).

17 Washington State Department of Health. Health data: guidelines for using rural-urban classification systems for public health assessment. http:// www.doh.wa.gov/Data/guidelines/RuralUrban.htm. (accessed 26 Aug 2005).

18 Purtilo RB. Rural health care: the forgotten quarter of medical ethics. Second Opin 1987;6:10-33.

19 Portilo R, Sorrell J. The ethical dilemmas of a rural physician. Hastings Cent Rep 1986;16:24-8.

20 Nelson WA, Pomerantz AS. Ethics issues in rural health care. Trustee 1992;45:14-5.

21 Cook AF, Joyner JC. No secrets on Main Street. Am J Nurs 2001;101:67, $69-71$. 